\title{
Editorial: \\ Education for a Public Health Workforce in Europe and Globally
}

\author{
Theodore H Tulchinsky MD MPH, ${ }^{1}$ \\ Martin McKee CBE MD DSc ${ }^{2}$
}

\begin{abstract}
During the past century, public health has made major contributions to longer and better lives, through prevention and control of communicable and noncommunicable diseases and injuries, not only in industrialized nations but also worldwide. Public health, delivered through the organized efforts of society, benefitted from sanitation, food safety, new and improved vaccines, better nutrition, and successful health promotion that addressed many of the major causes of morbidity and mortality and an increasingly diverse array of public health challenges. One of the core functions of public health is to ensure an adequately organized, trained and supported workforce. In this issue, we address the educational context for training a multidisciplinary workforce to meet the needs of a public health community facing rapidly evolving responsibilities and challenges. Our objective is to promote discussion about effective policies on the public health workforce by governments, universities, schools, civil society, and the international health community, coupled with recognition of the centrality of this topic for their funding and development agendas. This is especially vital during a period of economic distress when there are cuts in public funding, even as threats to health are expanding as a consequence of increasingly global forces. The reviews and case reports in this issue show the diversity of experiences and identify some common themes for future development. Sharing the experience of different parts of the world in training public health workers will, we believe, promote analytic and constructive thinking and practices about curricula, competencies, bachelor's level and postgraduate education, research needs, the role of government, professional and nongovernmental organizations, international accreditation and other important issues. This offers a basis for the coming decades to foster academic and practical environments that can provide a trained public health professional workforce in each country in Europe, and ultimately, globally.
\end{abstract}

\footnotetext{
${ }^{1}$ Deputy Editor, Public Health Reviews; Braun School of Public Health, Hebrew UniversityHadassah, Ein Karem, Jerusalem, Israel.

${ }^{2}$ London School of Hygiene and Tropical Medicine, London, United Kingdom.
}

Correspondence: Theodore H Tulchinsky at email tedt@hadassah.org.il 
Key Words: Health profession education, public health workforce, European health, global health

Recommended Citation: Tulchinsky TH, McKee M. Education for a Public Health Workforce in Europe and Globally. Public Health Reviews. 2011;33:7-15.

\section{THIS ISSUE OF PUBLIC HEALTH REVIEWS}

In 2002, Public Health Reviews, in its former iteration, published the Proceedings of a Conference on developing new schools of public health. ${ }^{1}$ In those Proceedings, one of us (MM) wrote in a Guest Preface:

"What have we learned from this experience? One thing is that the knowledge that is generated by schools of public health must be academically rigorous but also relevant to policy. 'Policy relevance' is no more an excuse for sloppy research than 'academic rigour' is for work that is essentially addressing idle curiosity. Another is that schools of public health must engage with the outside world while not being sucked into it to such an extent that they simply become cheap consultants. Most importantly, they must show to those with whom they come in contact, whether students, health care professionals, or those working in other sectors that public health is important and achievable.

The extremely diverse nature of schools of public health in western Europe is, to a large extent, the legacy of individual national characteristics. Each school reflects the conditions that gave rise to it in the first place and to the nature of the higher education and health system in which it is embedded. It is not possible to lift one model from one setting and expect it to work in another one. Yet some lessons can, in my view, be drawn. One is the importance of a strong link with the university system, either within it or very closely linked to it. A second is the need for strong links to the health care system, although this begs the question as to what part of that system, given the many actors involved. However I believe that these links should extend beyond just the system that provides public health services. A third is the need for links to the local community, including the non-governmental and private sectors."

Martin $\mathrm{McKee}^{2}$

In the decade since that meeting, the subject of public health education has been addressed only modestly in the literature on health professional education, ${ }^{3}$ while the subject of human resources for health has received much more attention, especially since the 2006 World Health Report: Human Resources for Health. ${ }^{4}$ In 2010, the Lancet published "Health 
Professionals For a New Century. ${ }^{5}$ Regrettably however, there is only passing reference to educating the public health workforce. We are trying in this issue to add to the discussion on public health education because we see this as a vital issue globally. The achievements and current and future problems of public health require great professionalism and great numbers in a workforce including many different professions united in efforts to improve population, and individual health.

Policy makers have largely ignored the crucial role of educating the public health workforce. The processes arising from the European Bologna Declaration designed to raise standards of higher education in Europe have struggled to accommodate the specificities of education of health professionals. The European Union, with its increasing focus on a narrow definition of economic growth, is in danger of undervaluing the wider benefits of public health research.

In this issue we include an inspiring preface by Donald Henderson, ${ }^{6}$ the leader of the smallpox eradication program, who offers his take on developing careers in public health. We include reviews of the past, present and future of public heath training in Europe ${ }^{7-10}$ and the Americas, ${ }^{11}$ with case studies from Canada, ${ }^{12}$ the United Kingdom, ${ }^{13}$ The Netherlands, ${ }^{14}$ Chile, ${ }^{15}$ Mexico, ${ }^{16}$ Bulgaria ${ }^{17}$ and Israel. ${ }^{18}$ We examine competencies for public health from British and American perspectives, ${ }^{19,20}$ the role of international donors in promoting schools of public health in Eastern Europe, ${ }^{21}$ future issues in public health research, ${ }^{22}$ the global efforts by the Centers for Disease Control to train field epidemiologists, ${ }^{23}$ and programs preparing leaders in health systems management. ${ }^{24}$ In a fascinating review, Bangdiwala and colleagues report on public health education in the world's most populous countries, India and China, ${ }^{25}$ both of which have seen remarkable achievements over the past 60 years.

Why is all this important? Governments, international organizations, and professional associations seek to improve health, developing responses to diverse communicable and noncommunicable disease, injuries and violence, and threats of mass violence and even genocide. The successes of public health up to now have been enormous, and the potential achievements ahead are also great, but all of this requires trained professionals. We cannot cover all the issues facing those training the public health workforce, especially the growing recognition that the bulk of the workforce will need to come from undergraduate schools of many backgrounds with specialized training at the graduate level. Curriculum issues and how they relate to competencies of graduates are addressed but mainly to advance the discussion of these issues and not to formulate solutions. 


\section{THE NEED FOR PUBLIC HEALTH EDUCATION}

Public health workforce development is vital in countries at all stages of development, all of which are confronted by inequalities in the health status of their populations, divided by region, race, ethnic identity, gender, residence status, and socioeconomic characteristics. Developed countries face complex issues of aging populations, a rising burden of chronic disease (e.g., obesity, diabetes) and the challenge of cost containment when faced with rising expectations and new technologies. Middle and low income countries, many still struggling with high levels of infectious diseases, are now recognizing that they face rapidly increasing rates of premature disability and death from noncommunicable diseases. Low income countries face the enormous challenges of weak funding systems and infrastructure and a lack of trained health personnel, especially in public health. This severely constrains their ability to address the double burden of disease arising from the combination of poverty, growth of middle class lifestyles, rapid population growth, and aging populations.

\section{LEARNING FROM HISTORY}

This special issue of Public Health Reviews looks at a diverse range of experience with education of the public health workforce. Rosenstock, Helsing and Rimer describe how the United States has risen to the challenge of developing a system of public health education to meet the needs of organizations operating at local, state and national levels, as well as those working in academic centers of teaching and research and myriad nongovernmental organizations, advocacy groups and foundations. ${ }^{11}$

Cole, Sim and Hogan trace the development of public health education in the UK from its origins in departments of social medicine within medical faculties to multi-disciplinary groupings in universities of all types. The creation of a Faculty of Public Health has, in the past, done much to promote the professionalization of multidisciplinary public health, facilitated by a well-developed training structure within the National Health Service (NHS), although, at the time of writing, both universities and the NHS are under threat from a Conservative-led government pursuing a radical neoliberal agenda, as indeed is the public health infrastructure. ${ }^{26}$ The Faculty has played a particularly important role in developing a framework of competencies for public health, providing an illustration of the importance of professionalization of the discipline. ${ }^{8}$ 
The experience of public health education in Western Europe, reviewed by Paccaud, Weihofen and Nocera, identifies the constraints faced by departments of public health based in medical faculties, still the dominant position in many countries. ${ }^{7}$ The emergence of new schools of public health in Central and Eastern Europe and the former Soviet Union, reviewed by Adany and colleagues ${ }^{9}$ illustrates the challenges, and some solutions, in moving from a very narrow conceptualization of public health, characterized by the Soviet model of sanitary and epidemiological functions, with their focus on infectious disease, to one addressing the broader determinants of health. ${ }^{27}$ Overall and Goodman present the vital role of non-governmental agencies such as the Soros Foundation in stimulating reform in public health education in the former socialist countries of Central and Eastern Europe. ${ }^{21}$

The weakness of public health in many developing countries necessitates a stronger commitment to developing local capacity for public health education at all levels but particularly, for community health workers. Experiences in countries such as China are but one example. ${ }^{15}$ It will be of paramount importance to achieve the "catch up" needed in countries failing to achieve the Millennium Development Goals.

\section{THE CONTINUOUS EVOLUTION OF PUBLIC HEALTH CONCEPTS}

The scope of public health has evolved continuously from the sanitary movement of the $19^{\text {th }}$ century through the $20^{\text {th }}$ century with increasingly effective collective measures such as immunization and health education to strategies that address the determinants of health acting at a population level. This has been underpinned by advances in research methods, in aetiological epidemiology (such as advances in survey methods, the use of biomarkers, Mendelian randomization, and genome-wide association studies), in effectiveness research (such as randomized controlled trials, both individual and cluster), and in advanced quantitative and qualitative methods. This evolution has greatly expanded the scope of public health knowledge.

There has been equally significant growth in our understanding of the determinants of health, moving progressively upstream from an early focus on individual lifestyles to the consideration of the built and social environments in which people live and the factors that facilitate (e.g., safe and attractive open spaces, social capital) or impede (e.g., powerful vested interests such as the tobacco and alcohol industries) the pursuit of healthy choices.

Finally, there is now a much better understanding of Implementation Science, ranging from the adaptation of complex interventions in the local context to Force Field and Stakeholder Analysis and insights from political science to understand what needs to be done to effect real outcomes. Again, 
this has been accompanied by a greater awareness of the powerful industry forces with an interest in promoting products that damage health and the adverse health consequences of some political ideologies, historically exemplified by the failures of communism but now by the neoliberal agenda being pursued in a few countries.

Development of competency-based educational approaches for public health education programs is discussed in the European context by Birt and Foldspang, ${ }^{19}$ and in the US by Calhoun and colleagues. ${ }^{20}$ Preparing individuals within the public health workforce for leadership roles in managing health systems is also part of the educational needs in this field, because public health and preventive medicine are inescapably linked in the pursuit of better health and efficiency, as discussed by Kimberly. ${ }^{24}$ The vital interaction of research and education in public health is addressed by Ness. ${ }^{22}$

This illustrates the tremendous scope of modern public health and the challenges involved in training researchers and practitioners. Training programs must produce both generalists and specialists, all of whom must have the skills to work in different environments. This volume of PHR can, hopefully, help those who are contemplating how such complex and challenging needs can best be met.

\section{LEARNING FROM CASE REPORTS}

While public health education should be informed by rigorous research on what works, we also believe that it is possible to learn, and in many cases be inspired by, and lessons to be learned from the experiences of others. Consequently we have included a series of case reports, on topics such as the development of bachelor's and master's training programs at a new university in the $\mathrm{UK}^{13}$ and at Maastricht University in The Netherlands ${ }^{14}$; the global mentoring activities of experienced staff of the Braun School of Public Health in Jerusalem ${ }^{18}$; and the challenges of adapting to public health education needs in Austria and Germany. ${ }^{10}$

We can learn from how Canada reinvigorated its public health training after severe weaknesses were revealed by the SARS epidemic of 2003, with the strengthening of federal public health institutions and the creation of eight academic public health centres since 2006. ${ }^{12}$ Canada provides a cautionary tale for governments in other countries that see public health as a soft target as they struggle to adjust to the global economic crisis brought about by negligent and incompetent financial institutions in 2008. ${ }^{28}$

Schools of public health in Chile, ${ }^{15}$ Mexico, ${ }^{16}$ and Bulgaria ${ }^{17}$ provide examples of national approaches to implementing academic training in challenging and resource constrained circumstances. 


\section{MOVING FORWARD}

This volume sets out the challenges and identifies successes and failures in addressing them. The picture that emerges is one of considerable achievement but also indicates that much more needs to be done. Public health training is now well-developed in a few countries, such as Israel, the Nordic countries, Spain, The Netherlands, the UK, and the US, but in several of these countries it is now under threat. As the example of Canada shows, short term fixes to balance budgets often cost more in the long term. Governments, especially those with a neoliberal ideology, often forget (or more likely ignore) how health is a key driver of economic growth. ${ }^{28}$ In the US, a shortage of public health workers is developing as population growth, retirements, and austerity cutbacks in state and local governments indicate the need for increased enrollment in schools of public health, more undergraduate bachelor's level training, career ladders, and increased training at master's and doctorate levels. ${ }^{29}$ This applies in Europe as well. There is a need for public health professionals to proclaim what they have achieved, what more they can achieve in the future, and the dangers of failing to invest in a skilled public health workforce. We hope that the papers in this issue of Public Health Reviews will encourage them to do so.

A hopeful sign of significant progress is presented in the article by Otok, Levin, Sitko and Flahault ${ }^{30}$ on the new accreditation agency in Europe (APHEA). After several decades of trials with sponsorship by various agencies and NGOs, a body of knowledge and experience has been built up in Europe, primarily through the Association of Schools of Public Health (ASPHER). This serves as the basis for transnational criteria, peer review and for international recognition of academic programs of education in public health in Europe. The new accreditation agency will now focus establishing a modern set of criteria and content guidelines for accreditation of Master of Public Health and for all public health educational programs across the European Region. This will provide assurance to candidates, students, potential employers and universities that their public health training programs meet not only national standards but international ones as well. As this body gains experience and recognition by national and international bodies, we can hope that in the coming decade it will extend its work to include Bachelor's degree programs in public health and, equally important, to accreditation of public health agencies."

\footnotetext{
* Note: The final paragraph of this editorial was added after the first print run of this issue of Public Health Reviews. It will appear in any and all subsequent printings.
} 


\section{REFERENCES}

1. Tulchinsky TH, Epstein L, Normand C (Editors). Proceedings of the International Conference on Developing New Schools of Public Health, Jerusalem, 17-21 March, 2002. Public Health Reviews.2002;30:1-392.

2. McKee M. Foreward. Public Health Reviews. 2002;30:5-10.

3. Beaglehole R, Dal Poz MR. Public health workforce: challenges and policy issues. Hum Resour Health. 2003;1:4.

4. World Health Organization. World Health Report 2006: Human Resources for Health. WHO, Geneva. 2006.

5. Frenk J, Chen L, Bhutta Z, Cohen J, Crisp N, Evans T, et al. Health professionals for a new century: transforming education to strengthen health systems in an interdependent world. Lancet. 2010;376(9756): 1923-58.

6. Henderson DA. Preface: On the eradication of smallpox and a public health career. Public Health Reviews. 2011;33:19-29.

7. Paccaud F, Weihofen A, Nocera S. Public health education in Europe: old and new challenges. Public Health Reviews. 2011;33:66-86.

8. Cole K, Sim F, Hogan H. The evolution of public health education and training in the United Kingdom. Public Health Reviews. 2011;33:87-104.

9. Adany R, Villerusa A, Bislimovska J, Kulzhanov M. Public health education in Central and Eastern Europe, and Central Asia. Public Health Reviews. 2011; 33:105-33.

10. Noack H. Governance and capacity building in German and Austrian public health since the 1950s. Public Health Reviews. 2011;33:264-76.

11. Rosenstock L, Helsing K, Rimer BK. Public health education in the United States: then and now. Public Health Reviews. 2011;33:39-65.

12. Massé R, Moloughney B. New era for schools of public health in Canada. Public Health Reviews. 2011;33:277-88.

13. Aceijas C, Foster N. Public health capacity building in times of austerity: a case study from the University of East London. Public Health Reviews. 2011;33:240-50.

14. Kuiper T, Meijer A, Moust J. Innovation in public health teaching: the Maastricht experience. Public Health Reviews. 2011;33:300-14.

15. Pino P, Solimano G. The School of Public Health at the University of Chile: origins, evolution, and perspectives. Public Health Reviews. 2011;33:315-22.

16. Magaña-Valladares L, Cooper K. The National Institute of Public Health: shaping public policy to advance population health in Mexico. Public Health Reviews. 2011;33:331-8.

17. Popova S, Georgieva L, Koleva Y. Development of public health education in Bulgaria. Public Health Reviews. 2011;33:323-30.

18. Neumark Y, Manor O, Berry EM. Promoting public health workforce training for developing and transitional countries: fifty-year experience of the Braun School of Public Health and Community Medicine, Jerusalem, Israel. Public Health Reviews. 2011;33:251-63. 
19. Birt CA, Foldspang A. The developing role of systems of competences in public health education and practice. Public Health Reviews. 2011;33:134-47.

20. Calhoun G, Wrobel, CA, Finnegan JR. Current state in U.S. public health competency-based graduate education. Public Health Reviews. 2011;33:14867.

21. Overall JW, Goodman J. The role of non-governmental organizations in development of schools of public health: an example from Eastern Europe and Central Asia. Public Health Reviews. 2011;33:168-89.

22. Ness RB. Public health research Priorities for the Future. Public Health Reviews. 2011;33:225-39.

23. Schneider D, Evering-Watley M, Walke H, Bloland PB. Training the global public health workforce through applied epidemiology training programs: CDC's experience, 1951-2011. Public Health Reviews. 2011;33:190-203.

24. Kimberly JR. Preparing leaders in public health for success in a flatter, more distributed and collaborative world. Public Health Reviews. 2011;33:289-99.

25. Bangdiwala S, Tucker J, Zodpey S, Griffiths S, Li LM, Reddy KS, Cohen M, Gross M, Sharma K, Tang JL. Public health education in India and China: history, opportunities, and challenges. Public Health Reviews. 2011;33:20424.

26. McKee M, Hurst L, Aldridge RW, Raine R, Mindell JS, Wolfe I, Holland WW. Public health in England: an option for the way forward? Lancet. 2011;378: 536-9.

27. Gotsadze G, Chikovani I, Goguadze K, Balabanova D, McKee M. Reforming sanitary epidemiological service in Central and Eastern Europe and the former Soviet Union: an exploratory study. BMC Health Serv Res. 2010;10:440.

28. McKee M, Suhrcke M. Investing in health: a contribution to achievement of the Lisbon Agenda. European Review. 2010;18: 9-21.

29. Murray LR. Future of public health workforce lies in better education, training: perspectives of the president of APHA. The Nation's Health. 2011;41:3.

30. Otok R, Levin I, Sitko S, Flahault A. European Accreditation of Public Health Education. Public Health Reviews. 2011;33:30-8. 